\title{
Growth and Characterization of ULMA Single Crystals Doped with Ammonium Chloride
}

\author{
B. Sivasankari ${ }^{1}$ and P. Selvarajan ${ }^{2}$ \\ ${ }^{1}$ Department of Physics, Kalasalingam University, Krishnankoil 626 190, India \\ ${ }^{2}$ Department of Physics, Aditanar College of Arts and Science, Tiruchendur 628 216, India
}

Correspondence should be addressed to P. Selvarajan; pselvarajanphy@yahoo.co.in

Received 3 December 2012; Revised 9 March 2013; Accepted 10 March 2013

Academic Editor: Steven Suib

Copyright (C) 2013 B. Sivasankari and P. Selvarajan. This is an open access article distributed under the Creative Commons Attribution License, which permits unrestricted use, distribution, and reproduction in any medium, provided the original work is properly cited.

\begin{abstract}
Single crystals of pure and ammonium chloride-doped urea L-malic acid (ULMA) were grown by slow evaporation technique. Many interesting results on several properties of ammonium chloride impurity added to ULMA single crystals have been observed and studied. The different morphology of ammonium chloride-doped ULMA crystals was noticed and the effect of ammonium chloride doping on the growth, optical, and hardness properties has been investigated. The presence of functional groups has been estimated by FTIR analysis. The lattice parameters of the grown crystals were studied by single crystal X-ray diffraction technique. Powder X-ray diffraction studies confirm the diffraction planes of the grown crystals. The UV-visible spectrum shows the cutoff wavelength at $220 \mathrm{~nm}$. A study on the thermal properties has also been carried out. The NLO property of the grown crystals was confirmed by SHG studies.
\end{abstract}

\section{Introduction}

Crystalline salts of amino acid complexes have recently attracted considerable interest among researchers due to its wide range of applications $[1,2]$. Urea L-malic acid (ULMA) is one such material and few reports are available on ULMA crystal in the literature [3-7]. However, there is no report available, to the best knowledge of the authors, on the doping of this material. ULMA crystallizes in the monoclinic system with space group $\mathrm{P} 2{ }_{1}$. The reported lattice parameters are $a=9.0335(8) \AA, b=6.9356(5) \AA, c=6.8008(6) \AA$, and $\beta=94.67(0)^{\circ}$ at $295 \mathrm{~K}[3,4]$. ULMA crystal has a wide transmission range in the visible region and could be used as a nonlinear optical (NLO) material. Microelectronics need low dielectric constant $\left(\varepsilon_{r}\right)$ materials and ULMA crystal has low values of dielectric constant, and hence it can be used to reduce the RC delay, reduce power consumption, and reduce cross talk. It is reported that doped NLO materials have more advantages than undoped materials $[8,9]$. Urea Lmalic acid (ULMA) is an organic material, and if an inorganic material like ammonium chloride is used as the dopant, it is expected that the physical and chemical properties of the host crystal; namely, urea L-mailc acid may be altered and NLO properties of ULMA crystal may be improved, and hence in the present investigation, pure and ammonium chloridedoped urea L-malic acid (ULMA) single crystals were grown by slow evaporation technique. The grown crystals were characterized by FTIR, single crystal XRD and powder XRD studies, UV transmission, hardness, TG/DTA, and SHG studies. The results obtained from various studies of undoped and ammonium chloride-doped ULMA crystals are here reported and discussed.

\section{Experimental Studies}

2.1. Crystal Growth and Morphology. High-purity chemicals with deionized water were used to grow crystals by slow evaporation technique. Urea and L-malic acid were taken in 1:1 molar ratio, and ammonium chloride was added in three different weight percentages of $5 \mathrm{wt} \%, 10 \mathrm{wt} \%$, and $15 \mathrm{wt} \%$ to the solution of urea L-malic acid. Uniform stirring was maintained and the temperature and volume were also kept constant as $307 \mathrm{~K}$ and $100 \mathrm{~mL}$ for all crystals to grow. 


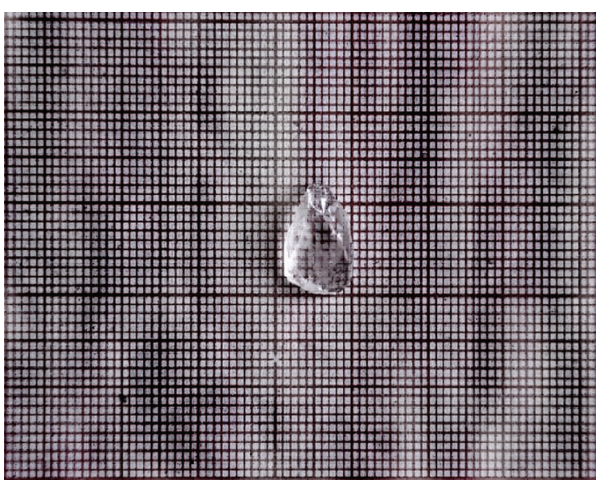

(a)

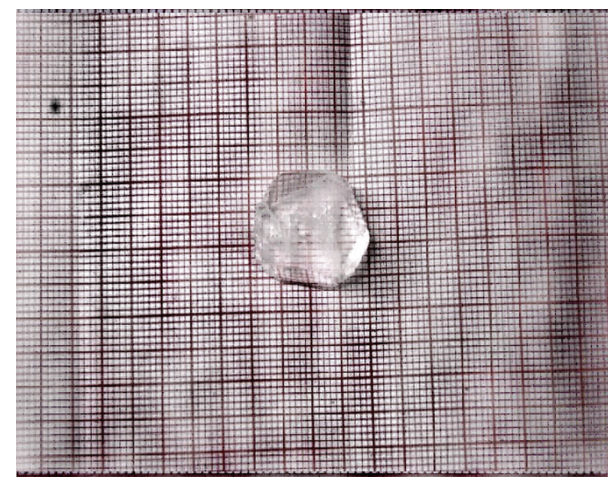

(b)

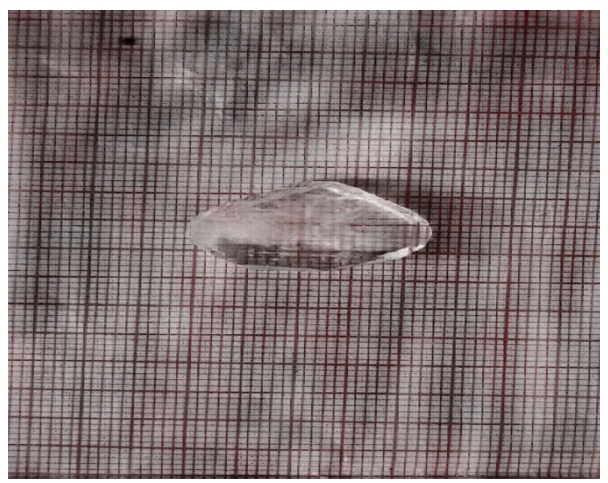

(c)

Figure 1: A photograph showing ammonium chloride doped ULMA crystals. (a) ULMA doped with ammonium chloride, (5 wt\%), (b) ULMA doped with ammonium chloride, (10 wt\%), (c) ULMA doped with ammonium chloride, (15 wt\%).

Nuclei started to appear in the saturated solution after 15 days and crystals of size $20 \times 10 \times 7 \mathrm{~mm}^{3}$ have been observed after the growth period of 35 days. From these grown crystals, defect-free crystals were selected and used for the studies. Figure 1 shows the as-grown crystals of ULMA doped with different weight percentages of ammonium chloride. In our study, crystallization indicates that dopant addition of different weight percentages of ammonium chloride to ULMA results in a change of crystal habit. Low concentrations of ammonium chloride as impurity were found not to affect the prismatic faces of pure ULMA. ULMA crystal grown from ammonium chloride of $5 \mathrm{wt} \%$ as dopant was found to have prismatic shape. With increasing the dopant percentage addition from $10 \mathrm{wt} \%$ to $15 \mathrm{wt} \%$, extra faces with platy habit were found in the grown crystals. As reported in literature [10], it may be due to adsorption which led to changes in growth mechanism and habit modification. The supersaturation and stirring may be also found to affect the crystal habit.

2.2. Characterization Techniques. To analyse the presence of functional groups, Fourier Transform Infrared Spectrum (FTIR) was recorded using a Shimadzu spectrophotometer with $\mathrm{KBr}$ pellet technique in the range of 4000 to $500 \mathrm{~cm}^{-1}$. Single crystal X-ray diffraction data have been collected using Enraf Nonius CAD-4 Diffractometer $(\lambda=0.7107 \AA$ in $\omega / 2 \theta$ mode) with graphite monochromated $\mathrm{Mo} \mathrm{K}_{\alpha}$ radiation.
Powder XRD was recorded by employing a powder X-ray diffractometer (PANalytical multipurpose diffractometer) with nickel filtered $\mathrm{Cu} \mathrm{K}_{\alpha}$ radiation $(\lambda=1.54056 \AA)$. The UVvisible-IR transmission spectrum of ULMA was recorded on a SHIMADZU UV-240 IPC spectrophotometer in the range of 190-1100 nm. Single crystals of ULMA of thickness of $1 \mathrm{~mm}$ were used for this study. Vickers hardness measurements were carried out using ultramicrohardness tester fitted with a diamond indenter. The indentations were made using a Vickers pyramidal indenter for various loads from 25 to $200 \mathrm{~g}$. Several trials of measurements were made on the prominent (010) face, and the average diagonal length was calculated for indentation of $5 \mathrm{~s}$. Simultaneous TG and DTA were carried out using a thermal analyser SDT Q600 between 10 to $700^{\circ} \mathrm{C}$ at a heating rate of $20^{\circ} \mathrm{C} / \mathrm{min}$ in nitrogen atmosphere [11, 12]. Preliminary experiment was undertaken to observe secondorder nonlinear optical response, and the grown crystals were subjected to Kurtz powder test to find the nonlinear optical property [13]. The sample was illuminated with Nd:YAG laser using the first harmonics output of $1064 \mathrm{~nm}$ with pulse energy of $4.6 \mathrm{~mJ}$. Urea was used for calibrating the SHG intensity.

\section{Results and Discussion}

3.1. FTIR Analysis. FTIR spectrum of the grown crystals is shown in Figure 2. By the interpretation of FTIR spectra, it is possible to show that certain functional groups are present 


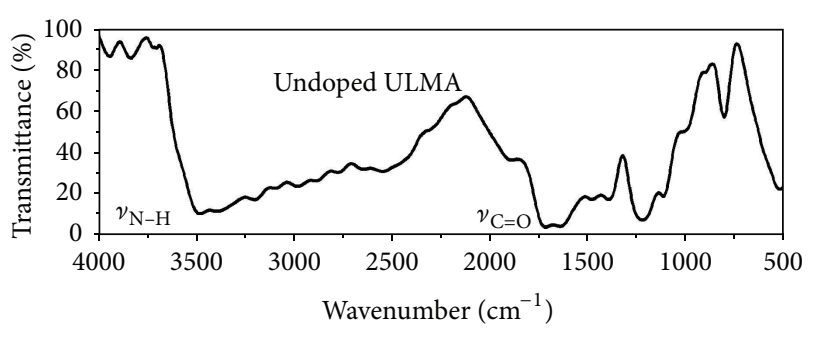

(a)

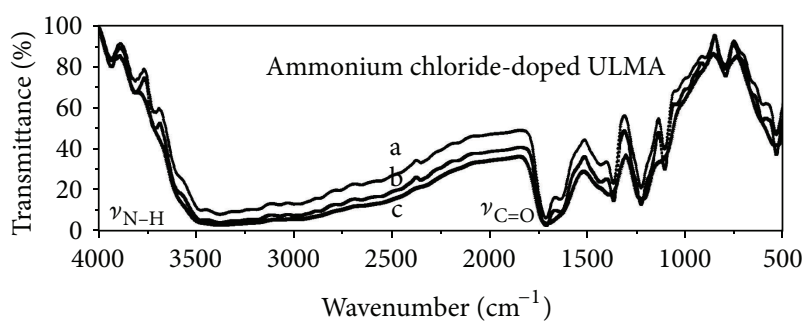

(a) $5 \mathrm{wt} \%$

(b) $10 \mathrm{wt} \%$

(c) $15 \mathrm{wt} \%$

(b)

FIGURE 2: FTIR spectra of the grown undoped and ammonium chloride-doped ULMA samples.

TABLE 1: Wave numbers of the absorption band maxima in the FTIR spectra of the grown samples.

\begin{tabular}{lcc}
\hline $\begin{array}{l}\text { Ammonium chloride } \\
\text { concentration in the } \\
\text { ULMA single crystal }\end{array}$ & $\begin{array}{c}\text { Wave number and assignments, }\left(\mathrm{cm}^{-1}\right) \\
\text { Stretching vibration } \\
\text { from amino groups }\end{array}$ & $\begin{array}{c}\text { Carbonyl stretching } \\
\text { vibrations }\end{array}$ \\
\hline $0 \mathrm{wt} \%$ & 3489.77 & 1637.45 \\
$5 \mathrm{wt} \%$ & 3459.75 & 1643.42 \\
$10 \mathrm{wt} \%$ & 3468.79 & 1641.45 \\
$15 \mathrm{wt} \%$ & 3474.73 & 1645.42 \\
\hline
\end{tabular}

in the material. The results of FTIR analysis obtained in our present work for undoped ULMA single crystal were found to be in good agreement with the reported value $[1,6]$. Intense band in the range of $3498-3250 \mathrm{~cm}^{-1}$ is due to stretching vibration from amino groups. An intense band in the range of $1645-1750 \mathrm{~cm}^{-1}$ is due to carbonyl stretching vibration. The FTIR peaks in ammonium chloride-doped ULMA crystals are wider than their corresponding peaks in undoped ULMA. The packing of ULMA in crystalline state is very peculiar due to hydrogen bonds as studied by de Matos Gomes et al. [7]. The assignments for the absorption peaks/bands of the FTIR spectra are given in accordance with the data reported in the literature $[6,14]$, and the frequency assignments for the absorption peaks corresponding to amino groups are provided in Table 1.

3.2. Single X-Ray Diffraction Studies. X-ray diffraction (XRD) was used for the identification of the crystal. The grown crystals were subjected to single crystal XRD studies, and

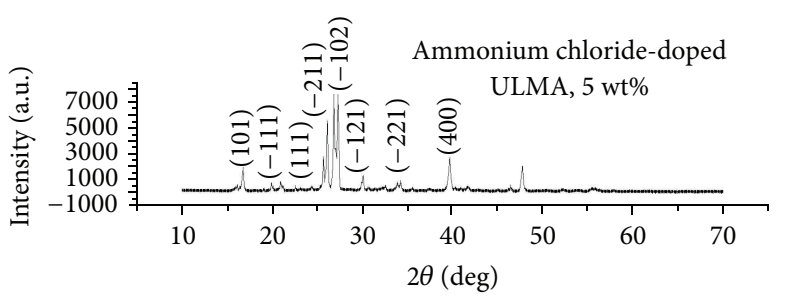

(a)

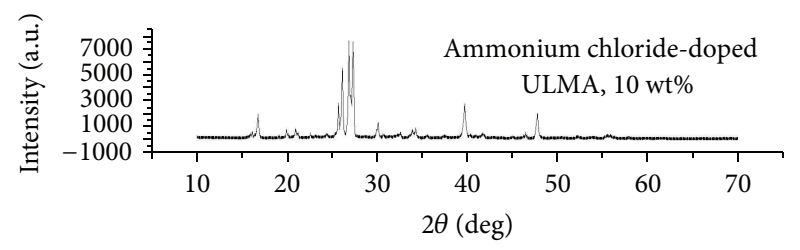

(b)

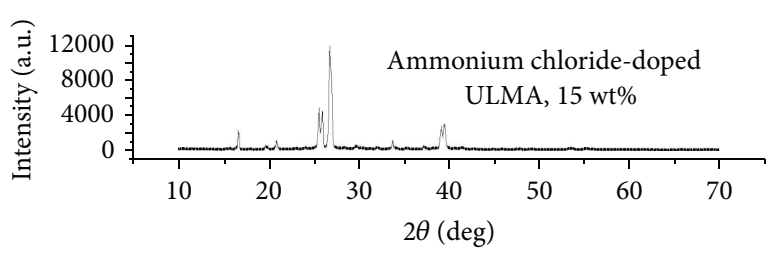

(c)

FIGURE 3: XRD patterns of the grown samples.

the obtained values crystal cell parameters are given in the Table 2. It is observed from the results that the grown undoped and ammonium chloride-doped ULMA crystals crystallize in the monoclinic system and a small variation is noticed in the values of the lattice parameters of doped ULMA crystals as compared to those of undoped ULMA crystal. The obtained lattice parameters of pure LLMA crystal are observed to be in close agreement with data reported in the literature $[3,4]$.

3.3. Powder X-Ray Diffraction Studies. Single crystal XRD studies give the values of unit cell parameters of the samples. To confirm the obtained values of unit cell parameters, powder XRD studies were also carried out for the samples of this work. Also powder XRD studies will give ideas of diffraction planes of the crystals. Figure 3 shows the powder XRD spectra of the grown samples, and all the observed reflection peaks were indexed. The observed and calculated $d$-spacing values and the corresponding (hkl) planes are provided in Table 3. Using the powder XRD data, the lattice parameters were obtained with the help of UNITCELL software package, and it is found that the lattice parameters obtained from the powder XRD studies are very close to the those obtained from single crystal XRD studies. The slight shift of the reflection peaks in the powder XRD patterns of the doped samples indicates that the dopant has entered into the lattice of the host crystal.

3.4. Optical Transmission Studies. The UV-visible-IR transmission spectrum of the grown samples was shown in 
TABLE 2: Unit cell parameters of the grown samples.

\begin{tabular}{|c|c|c|c|}
\hline \multirow{2}{*}{ Unit cell parameters for pure ULMA } & \multicolumn{3}{|c|}{ Unit cell parameters for ammonium chloride-doped ULMA crystals } \\
\hline & $5 \mathrm{wt} \%$ & $10 \mathrm{wt} \%$ & $15 \mathrm{wt} \%$ \\
\hline$a=9.045(3) \AA$ & $a=9.000(6) \AA$ & $a=9.000(5) \AA$ & $a=9.053(9) \AA$ \\
\hline$b=6.923(5) \AA$ & $b=6.934(4) \AA$ & $b=6.915(5) \AA$ & $b=6.919(5) \AA$ \\
\hline$c=6.814(4) \AA$ & $c=6.781(2) \AA$ & $c=6.727(3) \AA$ & $c=6.821(2) \AA$ \\
\hline$\alpha=\gamma=90.00(0)^{\circ}$ & $\alpha=\gamma=90.00(0)^{\circ}$ & $\alpha=\gamma=90.00(0)^{\circ}$ & $\alpha=\gamma=90.00(0)^{\circ}$ \\
\hline$\beta=94.88(1)^{\circ}$ & $\beta=94.61(1)^{\circ}$ & $\beta=94.60(1)^{\circ}$ & $\beta=94.59(1)^{\circ}$ \\
\hline$V=425(1) \AA^{3}$ & $V=422(2) \AA^{3}$ & $V=418(3) \AA^{3}$ & $V=426(2) \AA^{3}$ \\
\hline
\end{tabular}

TABLE 3: Theoretical and experimental $d$-values in $\AA$, hkl values for prominent peaks powder XRD patterns of the grown samples.

\begin{tabular}{|c|c|c|c|c|c|c|c|c|c|}
\hline \multirow{2}{*}{ Ammonium chloride-doped ULMA } & & \multicolumn{8}{|c|}{ Peak } \\
\hline & & 101 & -111 & 111 & -211 & -102 & -121 & -221 & 400 \\
\hline \multirow{2}{*}{$15 \mathrm{wt} \%$} & Theory $d$ & 5.312 & 4.502 & 4.241 & 3.425 & 3.322 & 2.922 & 2.566 & 2.118 \\
\hline & Calculated $d$ & 5.233 & 4.377 & 4.174 & 3.402 & 3.269 & 2.951 & 2.555 & 2.256 \\
\hline \multirow{2}{*}{10 wt $\%$} & Theory $d$ & 5.251 & 4.467 & 4.244 & 3.322 & 3.211 & 2.938 & 2.534 & 1.986 \\
\hline & Calculated $d$ & 5.175 & 4.347 & 4.143 & 3.38 & 3.227 & 2.941 & 2.580 & 1.974 \\
\hline \multirow{2}{*}{$5 \mathrm{wt} \%$} & Theory $d$ & 5.297 & 4.452 & 4.245 & 3.322 & 3.264 & 2.972 & 2.525 & 2.024 \\
\hline & Calculated $d$ & 5.201 & 4.366 & 4.161 & 3.389 & 3.250 & 2.951 & 2.586 & 2.031 \\
\hline
\end{tabular}

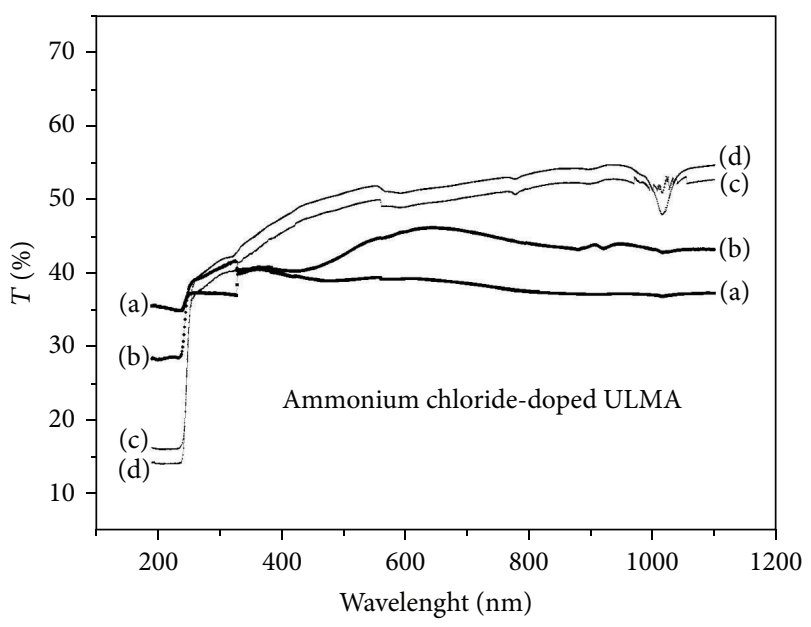
(a) undoped ULMA
(b) $5 \mathrm{wt} \%$
(c) $10 \mathrm{wt} \%$
(d) $15 \mathrm{wt} \%$

FIGURE 4: UV-visible-IR spectra of the grown samples.

Figure 4. For all optical applications in general and especially for SHG the material considered must be transparent in the wavelength region of interest. All crystals of undoped and ammonium chloride-doped ULMA can be utilized for second harmonic generation in visible wavelengths since the transparency is good in that range. An interesting result of increase in transmittance by the addition of ammonium chloride as impurity into ULMA crystal was observed. The transmittance increases by $45 \%, 52 \%$, and $54 \%$ for the ammonium chloride-doped ULMA crystals with

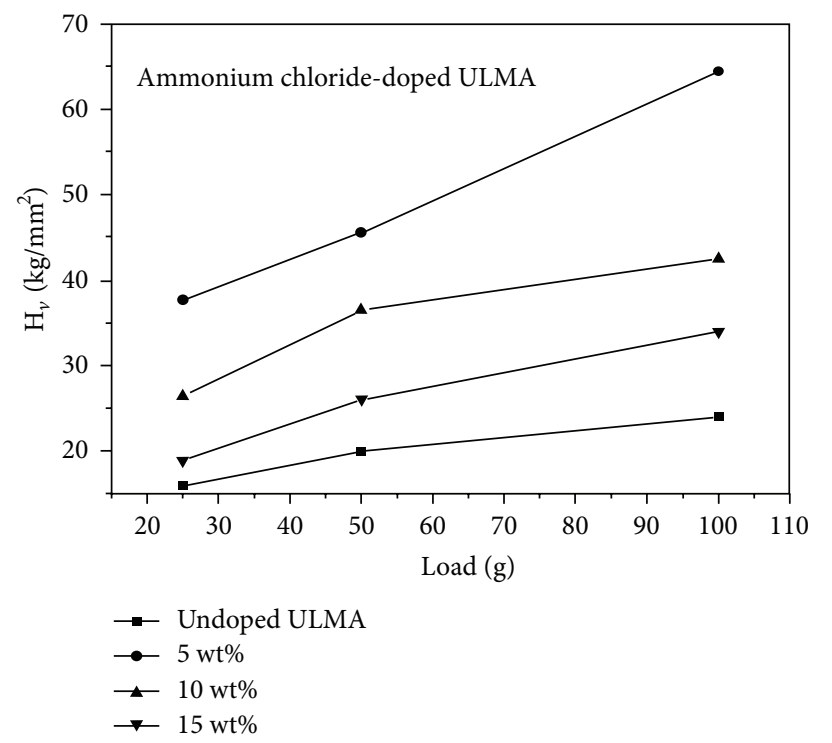

FIGURE 5: Variation of microhardness number with the applied load for pure and ammonium chloride-doped ULMA crystals.

doping concentration of $5,10,15 \mathrm{wt} \%$ respectively, in the visible region, and the transmittance is comparatively low by around $40 \%$ for undoped ULMA crystal. This shows that the ammonium chloride as impurity has not destroyed the optical transparency of the crystal, and it is found to suppress the inclusions and improves the quality of ULMA crystal with higher transparency range. The lower cutoff which corresponds to the fundamental absorption occurs at $220 \mathrm{~nm}$ for undoped ULMA crystal. When ammonium chloride was added as dopant to ULMA, it is observed that lower cutoff wavelength slightly increased. The short cutoff 


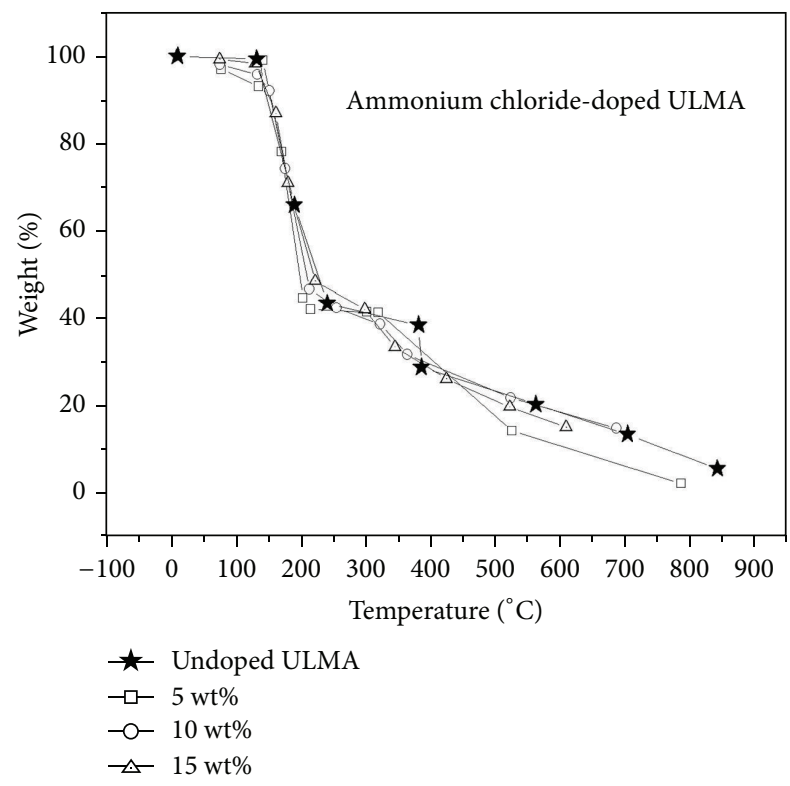

FIgURE 6: TGA curves for the grown samples.

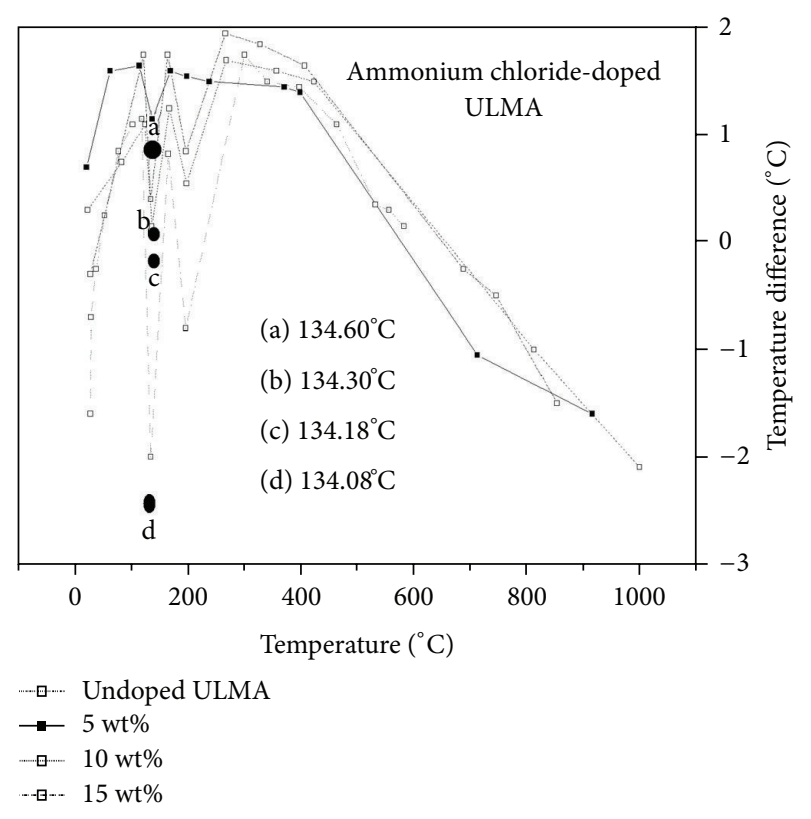

FIGURE 7: DTA curves for the grown samples.

wavelength facilitates the grown crystals of this work to be potential nonlinear optical materials for second harmonic generation. Absorption in the near ultraviolet region arises from electronic transitions associated within the samples. Using the formula $E_{g}=1240 / \lambda(\mathrm{nm})$ [15], the band gap is calculated to be $5.636 \mathrm{eV}$ for all the grown samples.

3.5. Microhardness Studies. Vickers hardness number was evaluated from the relation $H_{v}=1.8544 P / d^{2} \mathrm{~kg} / \mathrm{mm}^{2}$, where $H_{v}$ is Vickers hardness number, $P$ is the indenter load in kilograms, and $d$ is the diagonal length of the impression in millimetres [16]. Figure 5 shows the variation of microhardness values with applied load for the samples. The hardness value increases with increasing load. For loads above $200 \mathrm{~g}$ cracks developed on the surface of the crystal due to release of internal stress generated locally by indentation. It was observed that for low weight percentage concentration of ammonium chloride impurity, the microhardness is found to be more than double the times of pure ULMA single crystal. With the increase in higher impurity concentration, the strengthening decreases and the values of hardness are approaching those of pure ULMA crystal. This may be due to weakening the strength of bonds of the lattice of ULMA crystal as more weight percentage of dopants (ammonium chloride) are added. The results indicate that the mechanical properties could be increased with minimum selection of ammonium chloride as impurity.

3.6. TG and DTA Analysis. Figures 6 and 7 show the TG/DTA curves of pure and ammonium chloride-doped ULMA crystals. It is observed from the results that the melting point of ULMA crystal is slightly increased when low concentration of ammonium chloride was added as dopant. When the dopant concentration of ammonium chloride is more than $5 \mathrm{wt} \%$, the decomposition point is found to be decreased, and these results are also confirmed from microhardness studies. For all grown samples we found that there is no loss of water molecules before thermal stability point and also no endothermic peaks before decomposition are recorded. The sharpness of the thermograms is also illustrative of the crystal purity. More than one endothermic peak may be due to complex formation. For all the grown samples, gradual weight loss is noted up to the melting point. The decomposition point for all the samples is observed in the temperature range of $193-196^{\circ} \mathrm{C}$. The thermal stability is found to be more for all the samples and can be utilized in fabricating NLO devices. The obtained results are shown in Table 4.

3.7. Nonlinear Optical Test. The nonlinear optical (NLO) test was carried out for the samples and here an interesting result in SHG is observed. The second harmonic generation (SHG) is found to be appreciably increased by the addition of ammonium chloride as impurity into ULMA single crystal. The second harmonic generator wavelength was $532 \mathrm{~nm}$. At $15 \mathrm{wt} \%$ of ammonium chloride as impurity into ULMA crystal, the SHG efficiency is found to be more than double the times of that of urea. The results of SHG efficiency of the grown samples are shown in Table 5. The dopant "ammonium chloride" is an inorganic material, and if it is added to the lattice of ULMA, it is possible that the dopant may neutralize the $\mathrm{OH}$ group of ULMA, and this might be the cause of the enhanced second harmonic generation (SHG) efficiency. If $\mathrm{OH}$ group of ULMA is neutralized by doping ammonium chloride, the electron delocalization will be more in the doped samples, and this leads to enhancement of NLO property in the ammonium chloride-doped ULMA sample [17]. 
TABLE 4: TG/DTA results.

\begin{tabular}{|c|c|c|c|c|}
\hline & \multicolumn{3}{|c|}{ Compounds } & \\
\hline & \multirow{2}{*}{ Undoped ULMA } & \multicolumn{3}{|c|}{ Ammonium chloride-doped ULMA } \\
\hline & & $5 \mathrm{wt} \%$ & $10 \mathrm{wt} \%$ & $15 \mathrm{wt} \%$ \\
\hline \multicolumn{5}{|l|}{ TG } \\
\hline Stages of decomposition $\left({ }^{\circ} \mathrm{C}\right)$ & $\begin{array}{c}132.02,224.05 \\
386.32\end{array}$ & $\begin{array}{c}135.02,215.28 \\
320.00\end{array}$ & $\begin{array}{c}133.30,213.21 \\
322.16\end{array}$ & $\begin{array}{c}130.09,222.53 \\
298.80\end{array}$ \\
\hline Intial mass of the material subjected to analysis (mg) & 3.2600 & 2.7500 & 2.9430 & 0.7609 \\
\hline Residue (mg) & 0.0033 & 0.0381 & 0.0137 & 0.7609 \\
\hline \multicolumn{5}{|l|}{ DTA } \\
\hline Irreversible endothermic transition temperatures $\left({ }^{\circ} \mathrm{C}\right)$ & $132.08,194.72$ & $134.60,196.12$ & $134.30,195.98$ & $132.18,194.49$ \\
\hline Melting point $\left({ }^{\circ} \mathrm{C}\right)$ & 132.08 & 134.60 & 134.30 & 132.18 \\
\hline
\end{tabular}

TABLE 5: SHG efficiencies of the grown crystals.

\begin{tabular}{lc}
\hline Compounds & SHG efficiency \\
\hline Pure ULMA crystal & 0.34 times of urea \\
$5 \mathrm{wt} \%$ of ammonium chloride added to ULMA & 0.5 times of urea \\
$10 \mathrm{wt} \%$ of ammonium chloride added to ULMA & 1.32 times of urea \\
$15 \mathrm{wt} \%$ of ammonium chloride added to ULMA & 2.4 times of urea \\
\hline
\end{tabular}

\section{Conclusion}

ULMA crystals doped with ammonium chloride as dopant were grown and the morphology changes were noted. Grown crystals were characterized by single crystal and powder XRD studies and they confirmed that all the grown crystals belong to monoclinic system. Improvement in the optical transmission percentage and mechanical strength has been observed with ULMA crystal due to ammonium chloride as impurity addition. Hardness, thermal stability, and melting point were also determined for all the grown samples. The improved nonlinear optical properties of ammonium chloride-doped ULMA crystal proved it as a promising material for nonlinear application.

\section{Acknowledgments}

The authors would like to thank authorities of Aditanar College of Arts and Science, Tiruchendur, for the encouragement given to them to carry out the research work. Also they thank the staff members of M.K. University, Madurai, RRL, Trivandrum, St. Joseph's College, Trichy, Crescent Engineering College, Chennai, and CECRI, Karaikudi, for the characterization of the samples.

\section{References}

[1] A. S. J. Lucia Rose, P. Selvarajan, and S. Perumal, "Growth, structural, spectral, mechanical, thermal and dielectric characterization of phosphoric acid admixtured L-alanine (PLA) single crystals," Spectrochimica Acta A, vol. 81, pp. 270-275, 2011.

[2] S. A. Martin Britto Dhas, G. Bhagavannarayana, and S. Natarajan, "Growth and characterization of a new potential NLO material from the amino acid family-l-prolinium picrate," Journal of Crystal Growth, vol. 310, no. 15, pp. 3535-3539, 2008.

[3] V. K. Dixit, S. Vanishri, H. L. Bhat et al., "Crystal growth and characterization of a new nonlinear optical material: urea LMalic acid," Journal of Crystal Growth, vol. 253, no. 1-4, pp. 460466, 2003.

[4] S. Moitra and T. Kar, "Studies on the crystal growth and characterization of urea l-malic acid single crystals grown from different solvents," Materials Letters, vol. 62, no. 10-11, pp. 1609$1612,2008$.

[5] L. Zhu, J. Zhang, D. Chen et al., "Characteristics of an organic nonlinear optical material urea L-malic acid film," Materials Letters, vol. 60, no. 13-14, pp. 1740-1743, 2006.

[6] A. Deepthy, S. Vanishri, D. Ambika et al., "Photoacoustic investigations on thermal anisotropy in urea 1-malic acid single crystals," Materials Research Bulletin, vol. 43, no. 7, pp. 16411648, 2008.

[7] E. de Matos Gomes, V. Venkataramanan, E. Nogueira et al., "Synthesis, crystal growth and characterization of a new nonlinear optical material-urea L-malic acid," Synthetic Metals, vol. 115, no. 1, pp. 225-228, 2000.

[8] P. Selvarajan, J. Glorium Arul Raj, and S. Perumal, "Characterization of pure and urea-doped $\gamma$-glycine single crystals grown by solution method," Journal of Crystal Growth, vol. 311, no. 15, pp. 3835-3840, 2009.

[9] C. Krishnan, P. Selvarajan, and S. Pari, "Synthesis, growth and studies of undoped and sodium chloride-doped Zinc Tris-thiourea Sulphate (ZTS) single crystals," Current Applied Physics, vol. 10, no. 2, pp. 664-669, 2010.

[10] R. J. Davey, J. W. Mullin, and M. J. L. Whiting, "Habit modification of succinic acid crystals grown from different solvents," Journal of Crystal Growth, vol. 58, no. 2, pp. 304-312, 1982.

[11] M. Senthil Pandian and P. Ramasamy, "Growth and characterization of solution-grown tetra glycine barium chloride (TGBC) single crystals," Journal of Crystal Growth, vol. 310, no. 10, pp. 2563-2568, 2008.

[12] I. Quasim, A. Firdous, B. Want, S. K. Khosa, and P. N. Kotru, "Single crystal growth and characterization of pure and sodiummodified copper tartrate," Journal of Crystal Growth, vol. 310, no. 24, pp. 5357-5363, 2008.

[13] K. Betzler, H. Hesse, and P. Loose, "Optical second harmonic generation in organic crystals: urea and ammonium-malate," Journal of Molecular Structure, vol. 47, pp. 393-396, 1978.

[14] C. J. Pouchert, The Aldrich Library of Infrared Spectra, Aldrich Chemical Company, Milwaukee, Wis, USA, 3rd edition, 1981. 
[15] B. Sivasankari and P. Selvarajan, "Characterization of urea L-malic acid (ULMA) crystals grown in water, acetone and ethanol," Journal of Experimental Sciences, vol. 1, pp. 1-3, 2010.

[16] B. Helina, P. Selvarajan, and A. S. J. Lucia Rose, "Structural, optical, thermal, Mechanical and dielectrical characterizations of $\gamma$-glycine crystals grown in strontium chloride solution," Physica Scripta, vol. 85, pp. 055803-055808, 2012.

[17] P. V. Dhanaraj, C. K. Mahadevan, G. Bhagavannarayana, P. Ramasamy, and N. P. Rajesh, "Growth and characterization of KDP crystals with potassium carbonate as additive," Journal of Crystal Growth, vol. 310, no. 24, pp. 5341-5346, 2008. 

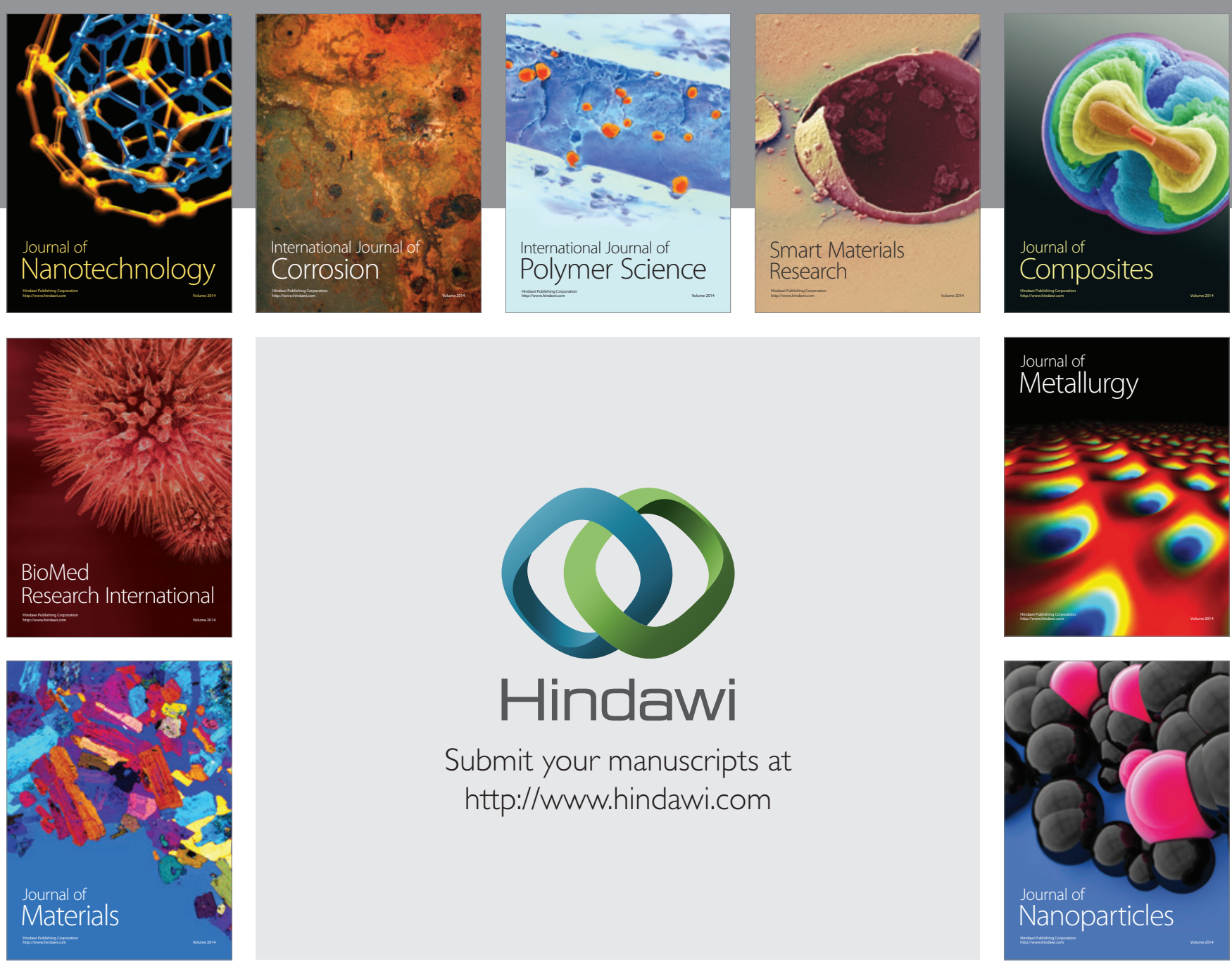

Submit your manuscripts at http://www.hindawi.com
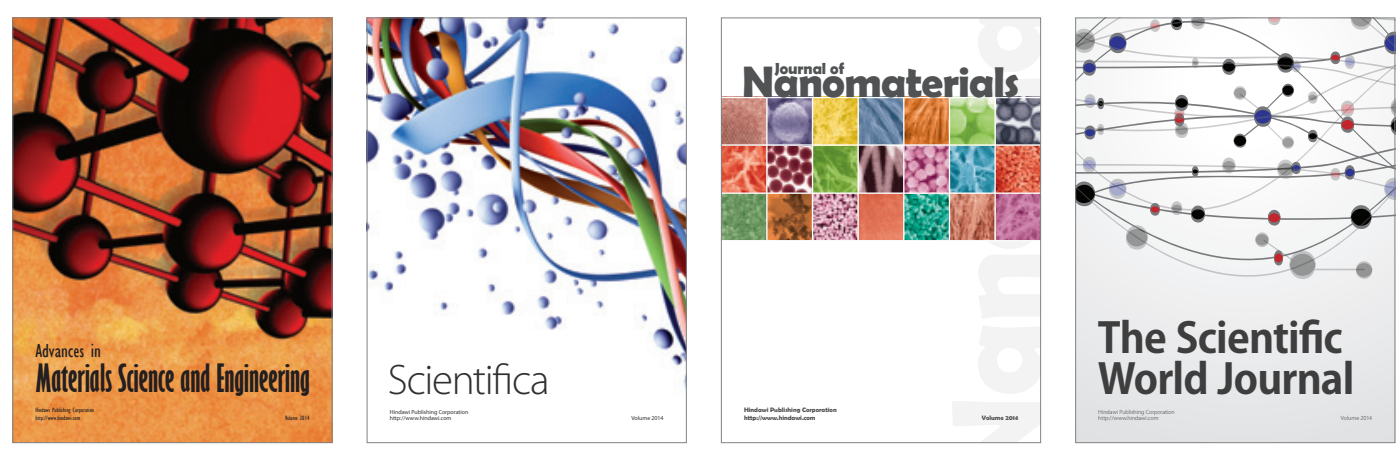

\section{The Scientific World Journal}
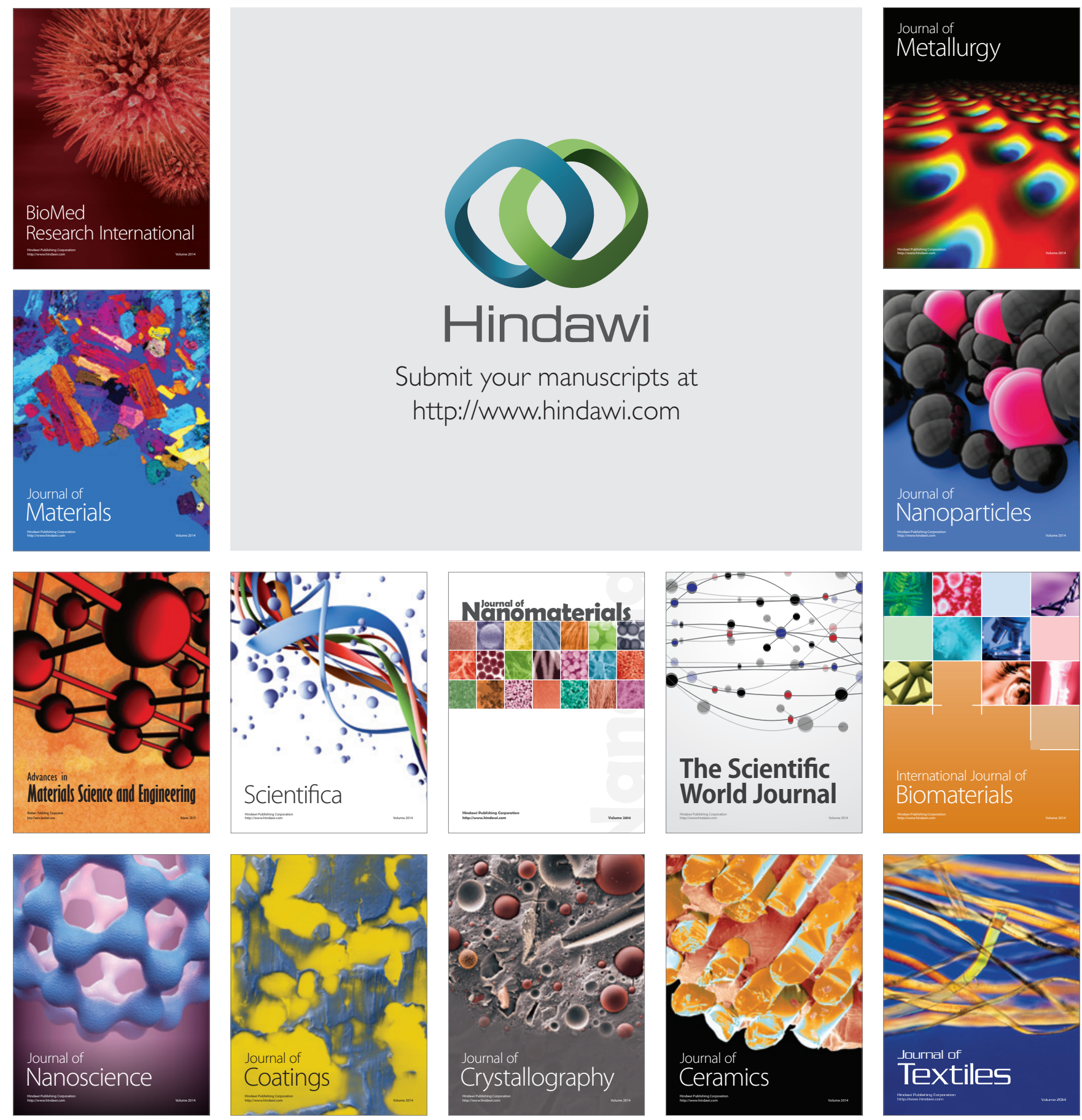